\title{
Practical Social Research
}


Also by the authors

\section{David Hall}

Social Relations and Innovation: Changing the State of Play in Hospitals

Beyond Separation: Further Studies of Children in

Hospital (with M. Stacey)

\section{Irene Hall}

Community Action versus Pollution 


\title{
Practical Social Research
}

\author{
Project Work in the \\ Community
}

\author{
David Hall \\ and \\ Irene Hall
}

Consultant Editor: Jo Campling

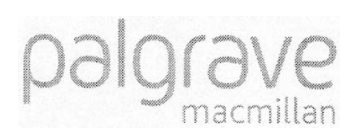


All rights reserved. No reproduction, copy or transmission of this publication may be made without written permission.

No paragraph of this publication may be reproduced, copied or transmitted save with written permission or in accordance with the provisions of the Copyright, Designs and Patents Act 1988, or under the terms of any licence permitting limited copying issued by the Copyright Licensing Agency, 90 Tottenham Court Road, London W1P 9HE.

Any person who does any unauthorised act in relation to this publication may be liable to criminal prosecution and civil claims for damages.

First published 1996 by

MACMILLAN PRESS LTD

Houndmills, Basingstoke, Hampshire RG21 6XS

and London

Companies and representatives

throughout the world

ISBN 978-0-333-60674-2 ISBN 978-1-349-24739-4 (eBook)

DOI 10.1007/978-1-349-24739-4

A catalogue record for this book is available from the British Library.

Transferred to digital printing 2003 


\section{Contents}

List of Tables xiii

List of Figures xiv

Glossary $\quad$ xv

Introduction and Acknowledgements 1

\section{PART I}

1 Philosophy and-Practice of Applied Social Research 9

The research adventure 9

Why practical research? 10

Philosophy of research 13

The client organisation 16

Gaining access 17

Stages of research 18

Personal transferable skills 20

Teamwork and group projects 22

Team dynamics 23

Group development 23

Unwritten contracts 24

Leadership 26

Overcoming group problems 26

Conclusion 27

2 Issues in Methodology 28

Which research method to choose? 28

Methods and methodology 29

Theory and data 30

Causal model 32 
Induction and deduction 33

Theory and evidence 35

The role of ideals 35

Models of research 37

The scientific model 37

Weber and the scientific model 40

The ethnographic approach 42

Validity 43

Reliability 44

Triangulation $\quad 44$

Evaluation research

45

Evaluators and programme staff 47

Alternative modes of evaluation 48

Further developments in methods of research 50

Social history 50

Critical methods 50

Action research 51

Feminist research methods 52

Conclusion $\quad 54$

3 Negotiating an Agreement 56

Introduction 56

Step 1: Contacting the organisation $\quad 57$

Networking 58

Listings $\quad 58$

Previous projects $\quad 58$

First contact 59

Step 2: The initial meeting 60

Organisation checklist 62

Step 3: Negotiating the project 63

Things to ask the organisation about itself and the proposed project 64

Things to tell the organisation about what you have to offer 66

Step 4: Negotiating the research design 68

Issues to be negotiated 68

Step 5: The outcome - a negotiated

agreement 72 


\section{Contents}

Conclusion $\quad 73$

Research Exchange 74

4 From Agreement to Research Brief 76

Purpose of the research brief $\quad 76$

Format 78

Contents 78

Practical considerations for evaluation $\quad 79$

How specific should you be on numbers and methods? 81

Practical considerations for undertaking research 83

Complications of access in health care settings $\quad 86$

Harm and benefit, and voluntary informed consent 86

The research action plan 88

Flexibility 88

Time management $\quad 89$

Using meetings 90

Research diary or log 91

Task management 91

Task and time schedule 92

Conclusion 94

\section{PART II}

5 Producing Data: the Questionnaire 97

Introduction $\quad 97$

What is a questionnaire? $\quad 98$

What form can questions take?

99

Advantages and disadvantages of the different uses

of questionnaires $\quad 99$

Self-completion, no researcher present $\quad 99$

Self-completion in group, with researcher present 100

Interview, face to face 101

Interview by telephone 102

Choice of method 103 


\section{Contents}

What to ask? 104

The data matrix 105

Sampling $\quad 106$

Representativeness $\quad 107$

Random sampling 109

Quasi-random sample 110

Stratified random sample 111

Random multi-stage cluster sample 111

Non-random sampling $\quad 112$

Quota sample 112

Snowball sample 113

Judgement sample 114

Accidental or convenience sample 115

Sample size 116

Stage 1: Consult similar research and

questionnaires 117

Stage 2: Identify topic areas and use

brainstorming 118

Stage 3: Work up each area into a set of questions 118

Avoid known pitfalls 120

Stage 4: Type out the questions and assemble in order, for scrutiny 122

Information for informants 124

Motivation and consent 124

Informal consent 125

Formal consent 126

Stage 5: Pre-test and pilot 126

Stage 6: Administer the questionnaire 127

Conclusion $\quad 128$

6 Data Analysis: the Questionnaire 129

In the beginning 129

Response rates 130

Frequency counts - closed questions 131

Percentages 132

Frequency counts - open-ended questions 133

Multiple responses 135

Forced-choice and ranking questions 136 


\section{Contents}

Measurement scales 137

Averages 139

Grouped data 141

Dichotomies 142

Univariate analysis 142

Graphical representation: bar charts and pie charts 143

Comparing variables: bivariate analysis $\quad 145$

Data matrix 146

Causal model 146

Tables $\quad 148$

Percentages $\quad 149$

Interpreting tables

Statistical tests 152

Putting it all together 153

Conclusion 154

Data analysis by computer $\quad 155$

7 Recording Data: Ethnography 156

Introduction $\quad 156$

Interviews 157

Structured $\quad 157$

Semi-structured $\quad 157$

Group $\quad 158$

Unstructured $\quad 159$

Choice of approach 160

Recording the interview - audio-tape recorder or notes? 161

Note taking 161

Tape recording 162

Ethical and practical considerations 163

Notes and tape 164

Producing the interview guide 164

The introduction 165

Briefing the informant 167

The setting 167

Ethnography and sampling 168

The role of the interviewer 171

Directiveness 172 


\section{Contents}

Probing and prompting 172

Withdrawal from the field 174

Reactivity 175

Reflective remarks $\quad 175$

Feminist concerns 176

Life history and oral history $\quad 180$

Life history 181

The life history in practical social research 182

Oral history 183

Oral history as part of practical social research 183

Oral history and feminist research $\quad 186$

Conclusion 187

8 Analysing Ethnographic Data 189

Time constraints: a cautionary note $\quad 189$

Data reduction $\quad 189$

Form of data record 190

Notepad 190

Tape recorder 191

Analysis with computers 192

Beginning the analysis 193

How will the data be presented? 193

Case studies 196

How can transcripts be transformed into a report? 198

Organising material - coding 199

Data matrix 201

Quantifying qualitative research 203

Oral and life history 204

Writing an oral history 205

Using other sources 207

Validity and reliability 208

Conclusion 211

9 Documentary and Other Sources 212

Available data 212

Official records 213 


\section{Contents}

Documents from organisations 214 Access to records 215 Using organisational records 216

Personal documents 217 The diary as research record 219 Mass media 221 Depicting the scene 222 Unobtrusive measures 223

Observation 224

Situated observation $\quad 225$

Conclusion $\quad 227$

\section{PART III}

10 Presenting the Client Report

One report or two? 231

Type of report 232

A product as project outcome 235

Guidelines for report writing 235

Be prepared to make revisions to your drafts 236

User-friendliness $\quad 237$

Structure of the report 238

Front cover 238

Preface 239

Abstract/executive summary 240

Background to the research 241

Findings 243

Selection and interpretation 244

Conclusions and recommendations

Appendix 247

Style of the report 248

Language and presentation 248

Focus on important points 250

Formatting $\quad 250$

Pagination 251

Length of the report 252

Dealing with potential problems with the report 252 


\section{Contents}

Assessment criteria 254

Teamwork and group reports 255

Conclusion 256

11 Presenting the Methodology or Reflexive Report 257

Methodology or reflexive report $\quad 257$

Reasons for the methodology report 258

Content of the methodology report 261

Context 261

Reflexivity 263

The unintended effects of doing research 263

Role relationships 264

From design to practice 268

Handling problems 270

The fieldwork diary 271

Evaluation 274

Written or oral report? 275

Assessment criteria 276

Conclusion $\quad 278$

Appendix A: Statement of Ethical Practice $\quad 279$

Appendix B: Agreement for Research 283

Appendix C: Oral History Consent Form 286

Bibliography $\quad 288$

Index $\quad 297$ 


\section{List of Tables}

5.1 Quota sample 113

6.1 Tally count - 'Have you ever been a volunteer?' 132

6.2 Tally count with percentages - 'Have you ever been a volunteer?' 133

6.3 Multiple response question - 'Why do you think people volunteer?' 137

$6.42 \times 2$ table: Opinions of men and women about volunteering 148

$6.52 \times 2$ table with percentages 150

8.1 The expectation of respondents 196

8.2 Data matrix 202 


\section{List of Figures}

1.1 Philosophy for applied social research 12

2.1 Simplified causal model of club attendance 32

2.2 The research process 38

3.1 Organisation checklist 62

4.1 Timescale of research 84

4.2 Task and time schedule 93

5.1 The data matrix 106

5.2 Sampling diagram 108

5.3 Snowball sample 114

6.1 Bar chart and commentary 144

6.2 Pie chart and commentary 145

6.3 Simplified causal model to explain attitude $\quad 147$

7.1 Interviewer directiveness scale 172

7.2 Reflective remarks 176

8.1 Tactics for drawing conclusions from qualitative data 203

8.2 A brief checklist of dimensions of bias 207

10.1 The report style 251 


\section{Glossary}

Client organisation: Used to denote the group with whom the research has been negotiated. A representative from this group is the recipient for the Client report produced by the student(s) as a result of their agreed practical research project.

Client report: The outcome of practical research, addressing the issues negotiated with the client organisation and written in everyday language. May include recommendations for action.

Community practitioner: Term currently used in Britain to denote those active at the locality level in providing welfare services.

Gatekeeper: Individual in an organisation with the power to grant access to a researcher.

Housing co-operative: A form of housing provision in Britain where residents are tenants of housing which they own in common (with government grant assistance), and which they are usually involved in planning, designing and administering.

Informant: Term used to denote the individual who is being asked for information, whether by interview or survey. Used instead of 'interviewee' or 'respondent' (also in common usage) as such an individual possesses the information which is the basis of the study $-s /$ he is the 'expert'. However, a study for women partners of prisoners could not use this term because of the negative connotation of 'informing'. 
Learning difficulty: Term currently used in Britain in preference to 'mental handicap' or 'mental retardation'.

Local authority: British term for local government at town, city or metropolitan area level which provides a number of services for residents and levies taxes.

Methodology report: Used to refer to a report which students may provide for their academic department as a reflection on their research experience and demonstrates the lessons they have learned about methodology in the everyday world.

Service user: Term in current usage which denotes the beneficiary of services, often of social care, from voluntary or statutory organisations. Used in the book in preference to 'client' - to distinguish from the official providers of the service (the client organisation).

Special needs: Term increasingly used in Britain in preference to 'disabled'.

Sponsor: Individual with influence who promotes research by providing researchers with the means and/or contacts for undertaking it.

Stakeholder: Refers to everyone in an organisation as provider or recipient of service, paid or voluntary staff who has some interest (stake) in the quality of service provided.

Survivor: Used as a non-stigmatising term instead of victim, as in survivor of rape

Voluntary organisations: Non-profit organisations, often either registered charities or voluntary associations, which usually include volunteers among their workers. In Britain increasingly dependent on paid staff, and major providers of specialised services to local authorities who contract to 'buy' such services (provided by, for example, residential homes or day centres). Called the Third Sector in the USA. 